\title{
The Influence of Subjective Factors on the Development of the Transformational Style of Leadership
}

Bilal EI TOUFAILI

\begin{abstract}
Managers have to face the complexity of the technological and informational environment, social change, increasing entrepreneurial activity, accelerating technological developments and a more educated and skilled workforce.

Leadership is a critical element in the success of an organization. Dynamic and efficient leadership involves creating a vision and action plan to ensure that organizations are client-centered, as well as creating a favourable environment for employees to optimize productivity and innovation.

Although the elements that can influence leadership are multiple, and with regard to the transformational leadership style is an interpretable measure of how it takes place, we consider it appropriate to analyse and measure the factors that contribute to its formation. The opportunity of undertaking this research derives from the need to identify the antecedents that contribute to the formation of the transformational leadership style.
\end{abstract}

Keywords: transformational leadership, subjective factors, motivation, leadership skills, organizational behaviour.

JEL classification: M12, M14, M19.

DOI: $10.24818 / \mathrm{RMCI} .2018 .2 .124$

\section{Introduction}

Leadership defines objectives, controls critical resources, and offers rewards through an interactive leadership process. In other words, leaders create an environment where followers can engage in creative efforts to achieve their goals. Therefore, instead of being dependent on power and control in management, future leaders should empower individuals to be their own leaders. Leadership involves focusing on a vision and inspiring subordinates to strive to achieve it in ways that have a positive impact on one's own goal while supporting a commitment integrity and truth (Adams and Spencer, 1986). This means that leadership should not only have a positive impact on individuals, but also include empowering them.

Whether it is a political, economic or social environment, leadership has proven to be essential to the growth and welfare of an organization (Bennis \& Nanus, 1985; Burns, 1978; Gardner, 1990). Effective and efficient leadership leads to the establishment of organizational missions, the achievement of objectives, the 
approach to problems through innovative methods and creativity, the execution of tasks, the development of a sense of trust and cooperation, and the growth and development of individuals (Greenleaf, 1998; Robbins \& Judge, 2011).

Burns (1978) launched the concept of "transformational leadership" through his descriptive research on political leaders and defines it as follows: "The transformational leader recognizes and exploits a necessity or demand from a potential person to follow. But, moreover, the transformational leader seeks to find the motivations of his subordinates, wants to meet high needs and involves the whole person in this process. The result of transformational leadership is a relationship of mutual stimulation and development that transforms subordinates into leaders and leaders into moral agents". The efficiency of the transformational leadership depends on a number of factors such as: the personality of the leader (Barbuto, 2005; Judge and Bono, 2000; Rubin et al., 2005) and the characteristics of the organizational environment (Bommer et al., 2004; Shivers-Blackwell, 2006). Leadership is the result of the action of a number of factors, including organizational culture, leadership qualities and characteristics, motivation systems and others such as hierarchical position, psychological and functional autonomy, information system and others. (Gîrneață \& Potcovaru, 2015). Transformational leadership is becoming more and more prominent at all levels of organizations (Toufaili, 2017). For this reason, leaders should learn how to empower subordinates to have skilled teams, which will increase productivity for the organization.

\section{What are the determinants of transformational leadership?}

The attempt to understand why some leaders succeed at the highest levels while others achieve average or below average results has maintained the interest of researchers and even leaders themselves. Over the years, a variety of constructs and predictors such as intelligence, personality, values, and even genetic factors have posited as leaders of leadership (Năstase et al. 2015). Stogdill (1974) argued that leadership is governed by personal and situational factors. When examining factors associated with leadership style, recent evidence suggests that leadership is the result of a complex interaction between biological, sociological and psychological factors of a person. In terms of biological factors that impact on leadership, researchers have shown that genetic factors such as general intelligence (Zacarro et al., 2004), height (Gladwell, 2005) and personality (Judge \& Bono, 2000) contribute to the formation of a leader.

Sociological factors also play a role in forming leadership skills. Influences such as parental style with which a child is raised (Avolio et al., 2009) and childhood experiences (Voelker et al., 2011) and maturity (Burke \& Attridge, 2011) a person's capabilities to become a leader. Also, a leader's own psychological processes influence performance and leadership skills. For example, researchers have demonstrated and highlighted the value and importance of emotional intelligence in the success of a leader (Goleman, 1998).

Review of International Comparative Management

Volume 19, Issue 2, May 2018 


\subsection{Personality traits}

The theories of personality traits start from the premise that personality is a hyper-complex, dynamic and open system that incorporates a set of features, characteristic modes of behaviour, knowledge, reactions and emotions. Research over the last 30 years has focused on transformational leadership, highlighting the existence of a clear and strong link with personality traits (Brandt \& Laiho, 2013; Brown \& Reilly, 2009). Although they have used different measurement tools for the two concepts, the results have shown that personality traits generally influence transformational leadership. Developed studies did not take into account the impact it might have on each component. Correlations tend to become more visible if a comparative analysis is carried out between the behaviours generated by different personality traits and those targeted by the four components of transformational leadership: idealized influence, inspirational motivation, intellectual stimulation, and individualized consideration.

Extraversion is one of the most important transformational leader personality factors (Trapnell and Wiggins, 1990; Watson \& Clark, 1997), facilitating behaviours associated with almost all components of transformational leadership, with the exception of inspirational motivation. Thus, he supports the leader's emotional expressiveness and engagement in the processes of persuasion, influence and mobilization of others (Gardner \& Avolio, 1998). Due to this and conformism, transformational leaders "tend to take the initiative in social environments, make presentations among participants in various actions, be sociable, with a sense of humour, introduce new topics of discussion and stimulate social interaction" (House \& Howell, 1992).

Conformism supports three of four components, namely: idealized influence, intellectual stimulation and individualized consideration. Thanks to this, the transformational leaders pay special attention to the members of the group, treat each subordinate separately and express their appreciation for the well done work (Lee, 2012). Thus, they are very sensitive to the needs of their subordinates (Wiggins, 1996) and encourage them to develop continuously.

Conscientiousness contributes to the development of the behaviours necessary for idealized influence, inspirational motivation and individualized consideration. Through a good self-determination and self-discipline, transformational leaders more effectively manage relationships with subordinates (Avolio et al., 1999) and set high, but accessible, performance standards (Barrick et al, 2001).

Nevrosity supports inspirational motivation and intellectual stimulation, although a negative relationship between neurosis and transformational leadership would be expected for a variety of reasons. First, setting high performance standards and motivating subordinates to achieve them requires a high level of confidence and self-esteem from the leader (Bass, 1985). Secondly, transformational leadership involves challenging the status quo and assuming risks that require a high degree of courage (Kirkpatrick \& Locke, 1991). Thus, the 
transformational leaders "must have a very high degree of self-confidence and moral conviction, because their mission is usually to diminish the resistance of those who want to keep the status quo" (House \& Howell, 1992). Transformational leaders also instil confidence in subordinates in a better future (Shamir et al., 1994), and this can only be achieved by registering a high level of self-confidence (Kirkpatrick \& Locke, 1991). Through neuroscience, the leader gains the subordinates' trust and presents a positive and convincing point of view (Yukl, 1998).

Opening towards experience only facilitates the behaviours that support intellectual stimulation as transformational leaders need to be creative and original (McCrae \& Costa, 1997). They are "not group facilitators, but active innovators. Their behaviours must be unusual, unconventional and out of the ordinary" (Conger \& Kanungo, 1987). They have a strong need for change and are able to understand and adapt to the perspectives of others. As a consequence, they are continually searching for new opportunities and experiences that can lead to personal development, subordinates and organization. To date, researchers have developed motivational constellations, as well as models that focus on independent personality factors (McCrae \& Costa, 1992).

\subsection{Education and professional experience}

The impact of leadership on company success continues to grow in importance in both the media and other research areas such as psychology, sociology (Schell et al., 2008). One of the key areas of leadership research involves examining successful business leaders to determine what differentiates them from their peers because researchers believe that leadership style efficiency has a direct relationship with business performance (Bill, 2003, Collins, 2001). The main institutional mechanism for the development of human capital is the formal education system: primary, secondary and tertiary. Because education is an investment, there is a significant positive correlation between education and economic-social productivity. When people are educated, their living standards increase what ultimately leads to an improvement in livelihoods. The role of education is therefore not just to share knowledge and skills, but also to give values, ideas, attitudes and aspirations important to natural development. Globally, educating a nation remains the vital strategy for the development of society around the world (Aikman \& Unterhalter, 2005).

There have been many studies on the training experiences that the leaders are developing effectively. Fundamental Theory presented in the Handbook of Leadership Development (McCauley et al., 1998) defines six experiences in developing a leadership style, three formal formulas - 360 degree, intensive feedback and competence-based training programs - and three informal - tasks at work, the development of relationships and the difficulties / difficulties they have experienced. In other researches, the authors examined what experiences and traits could make an effective leader. An example is the work of Bennis and Thomas, 
identifying what they called a "crucible leadership", the experiences that leaders have had either in business or elsewhere in life, and have shaped how they lead people (Bennis et al., 2002).

A study published in 2011 investigates how the level of education of a political leader affects economic growth in a country during its term, and especially whether more educated leaders generate greater growth. The sample consisted of 1,000 leaders who ruled the country between 1875 and 2004. The results demonstrated that intelligence is essential so that the idea/hypothesis that better educated citizens could be better leaders is confirmed (Besley et al., 2011). In assessing the impact of education on earnings, there may be a "pro-social bias" through which individuals choose to become more educated as a conscious or unconscious manifestation of their concern for social well-being. Whether it's talent or concern for social well-being, these results would explain why more educated leaders are better leaders. Punam Sahgal and Anil Pathak conducted a research in 2007 to study transformational leadership in the Indian context. It focused on the significant life experiences of leaders who contributed to success in organizations. Personal experiences shared by leaders provide valuable insights into the role of the family and childhood experiences that have had a sustained impact on their lives. Their work suggests that leaders do not appear as a consequence of events or incidents, but as a journey into life with distinct experiences. This study is based on the premise that the development of the psyche is the product of the process of socialization and analyses life experiences that have shaped the lives of leaders, who have transformed organizations to build a framework that exemplifies the development of transformational leaders. Social agents may be parents, friends, or colleagues and mentors at work. This research seeks to identify the experiences that lead to transformational leadership behaviours.

\subsection{Endogenous and exogenous motivation}

The term motivation comes from the Latin "move" or "moves" that illustrate moving. Motivation is a set of dynamic factors that determine human behaviour. Over time, several specialists have been concerned with studying the link between the transformational leadership style and motivation to work. For example, Barbuto (2005) has demonstrated that transformational leadership has a positive and significant influence on intrinsic motivation and there is a negative correlation with individualized consideration. A study was conducted on presidential leadership behaviour associated with job satisfaction, motivation for additional effort in different schools, colleges and universities. The results of the study show that there is a significant and positive influence between motivation and transformational leadership. Over the years, it has been demonstrated that transformational leadership and charismatic leadership are very important aspects that are strongly associated with managerial and organizational performance (Muchiri et al., 2012, Potcovaru \& Girneata, 2015). The effectiveness of leadership 
measures the ability of leaders to challenge subordinates to collective goals. Researchers exploring transformational and charismatic leadership should include the motivational effect in their study. The theory of transformational leadership is very important and many studies show that there is a positive relationship between it and other dependent variables such as employee satisfaction, commitment, motivation and performance.

Transformational leadership is surrounded by idealized influence, intellectual stimulation and inspirational motivation. Transformational leaders have a convincing vision that stimulates strong feelings, which contribute to increasing the perception of subordinates about ideal goals and contribute to inspiration to overcome their own interest in achieving collective goals. For example, Judge and Piccolo (2004) present the results of a meta-analysis showing that personality variables are consistently and reliably correlated with leadership variables. Chan and Drasgow (2001) demonstrate that a number of cognitive, personality and motivational constructs are linked to leadership on different samples from international environments. Schneider et al. (1999) show that a variety of personality constructs, interests and motivation can predict the leadership style among high school students. At the same time, we can say that motivation is a complete activity that any intelligent leader needs to pay attention to.

Garofoli (2002) talks about endogenous and exogenous local development. Endogenous development, according to the author, guarantees the autonomy of the process of transformation of the local economic system and is based on the production of "social capacity" at the level of the companies and institutions of the community by building the following capacities: the use of local resources (labour force, entrepreneurship, , material resources etc.), control of local accumulation process, control of innovation capacity, existence of interdependence between economic, social, cultural, environmental sectors. This type of development emphasizes the central role of local decision-making and the ability of social actors to control and internalize information from outside. Endogenous development means, in Garofoli's view, the ability to transform the socio-economic system, the ability to react to external change and the ability to introduce specific forms of social control at the local level. In contrast, exogenous is the externally controlled dependent development process. In practice, we can say that the two types of development intertwine, with external factors contributing to local development in collaboration with the social actors of the communities. According to the Garofoli (2002) description of endogenous and exogenous local development, we can relate to the same factors as the endogenous and exogenous motivation of an organization and not a community as described by the author.

Another concept found in literature is "motivation to drive". It has been developed as a broad theoretical framework for how individual differences influence the efficiency of leadership by taking into account both personal knowledge and individual factors such as personality, values and interests (Chan \& Drasgow, 2001). Chan and Drasgow define motivation to drive as a construct of individual differences that affect decisions about assuming leadership and 
responsibilities and which in turn affect the intensity of effort made by a leader within the organization in which they operate. Motivation to lead (the perception of being a leader is a duty or a responsibility) can influence leadership; however, the driving motivation component that has caused great interest in recent studies is that of affective-identity motivation to drive, that is, the motivation of people who want to be leaders or enjoy being in leadership roles. When affective-identity motivation to drive is great, leaders want to lead to enjoy doing it. In addition, the Theory of motivated action stated that the best predictors of favourite behaviours are behavioural intentions. As such, if people intend to be strong leaders and have the motivation to drive, they are more likely to have positive attitudes towards leadership. In this case they will adopt a transformational leadership style because of the need for personal development and growth.

People who are motivated and those who have leadership qualities "tend to be sociable, capitalize on their achievements and consort, and generally have a greater experience than their colleagues, and are confident in their leadership abilities" (Chan \& Drasgow, 2001). The second dimension, the social-normative motivation to lead, refers to the motivation of those who lead, because they consider this to be one of their responsibilities, and they feel a sense of duty or an obligation to lead. The third dimension, the (noncalculative) motivation to lead, assumes that people will be leaders only after they have to consider the costs in relation to the benefits. These leaders are motivated to lead only when they perceive personal benefits or benefits to do so.

\subsection{Other factors of a subjective nature}

Analysing the personal factors associated with leadership style, recent evidence suggests that leadership is the result of a complex interaction between the biological, sociological and psychological factors of a person. Numerous studies in various fields and disciplines such as psychology, education, economics and research claim that non-cognitive skills are important predictors of the ultimate success of an individual in life. Since decades of research have highlighted the importance of cognitive skills, such as general mental capacity (IQ), abstract reasoning, memory, knowledge and vocabulary, there is an increasing number of authors who have come to the conclusion that cognitive skills and a higher levels of intelligence are not always sufficient to drive individuals to the highest levels of success and achievement (Kaufman et al., 2013). Instead, there is an increase in the awareness of another set of variables called non-cognitive basic skills that are just as important, if not even more important, to ultimately determine the success of an individual (Jackson, 2013). These non-cognitive abilities include characteristics such as courage, motivation, self-control, hope, self-discipline, persistence, resistance, and other factors that seem to play a huge role in estimating the ultimate success of an individual education. Two basic non-cognitive skills that have received recent attention from researchers, practitioners and the media are hope and courage (Perkins-Gough, 2013).

$130 \quad$ Review of International Comparative Management Volume 19, Issue 1, May 2018 
Recent research shows that leadership is important in educational institutions and that effective schools often have strong leadership leadership. Marzano and Waters (2009) found that leadership traits and behaviours such as awareness of different situations, intellectual stimulation, change, and others are correlated with positive student outcomes, which suggests that leaders make a difference regarding the desired results by the educational institutions. Similarly, other scientists have also reported a positive relationship between intelligence and leader performance (Antonakis, 2011). These findings do not come as a surprise, because it would be hard for organizations to promote someone in a leadership position without clear evidence that that person is reasonably competent and intelligent. It was concluded that inherited aspects of personality and intelligence contribute seventeen percent to the emergence of an effective leader, leading the authors to conclude that people are indeed born with genetic predispositions to become leaders. Using modern neuroimagistic techniques, various assessments have shown that there are differences in brain functionality between effective leaders compared to less efficient leaders (Waldman et al., 2011). Other studies have had similar results, while effective leaders are susceptible to having parts of the brain that function differently in the frontal cortex, the brain region responsible for emotional regulation and emotional intelligence (Stackman \& Devine, 2011).

\section{Conclusions}

Recent evidence provided by neuroscience supports the idea that leadership is influenced by biological factors. Organizations increase their performance when leaders are able to attract loyal workers, define and inspire a clear and strong sense of mission, and determine employees to think they are joining to obtain something special.

In conclusion, transformational leaders generate greater involvement in the subordinates. This involvement leads to higher efficiency and satisfaction leading to managerial and organizational performance. In theory, the transformational leadership is positively correlated with a variety of organizational outcomes. From a theoretical point of view, literature offers empirical evidence and reinforces the belief that transformational leadership produces positive results for organizations. Organizations should consider education, work experience and motivation to better assess their employees and predict who might be efficient transformational leaders within the organization. This represents an important stage for organizations in the case of hiring or promoting managers from both inside and outside the company. Too many times, organizations take into account the possibility that the most prolific employees are also the best leaders or managers. While this would be ideal, it simply is not realistic. An efficient leader requires a set of different skills. Many people are not comfortable with leader responsibilities and deliberately avoid these positions because they do not feel they possess a set of skills or confidence to excel. 


\section{References}

1. Adams, J.D., \& Spencer, S.A. (1986). The strategic leadership perspective. In J. D. Adams (Ed.), Transforming leadership: From vision to results. Alexandria, VA: Miles River Press.

2. Antonakis (2011). Predictors of Leadership: The Usual Suspects and the Suspect Traits. Bryman et al. (Ed.). The Sage Handbook of Leadership. L.A.: Sage Publications

3. Avolio, B.J., Bass, B.M. \& Jung, D.I. (1999) Reexamining the components of transformational and transactional leadership using the Multifactor Leadership Questionnaire. Journal of Occupational and Organizational Psychology, Vol. 72, Nr. 4, pp. 441-462

4. Avolio, B., Walumbwa, F. \& Weber, T., (2009). Leadership: Current Theories, Research and Future Directions. Annual Review of Psychology, Volume 60, pp. 421-449.

5. Barbuto, J.E. Jr. (2005) Motivation and transactional, charismatic, and transformational leadership: a test of antecedents. Journal of Leadership and Organizational Studies, Vol. 11, Nr. 1, pp. 26-40.

6. Barrick, M. R., Mount, M. K., \& Judge, T. A. (2001). Personality and performance at the beginning of the new millennium: What do we know and where do we go next? International Journal of Selection and Assessment, 9, 930

7. Bass, B.M. (1985) Leadership and performance beyond expectations. New York: Free Press.

8. Bennis, W. \& Nanus, B.,(1985), Leaders: The Strategies for Taking Charge, New York: HarperCollins Publishers Group.

9. Bommer, W. H., Rubin, R. S., \& Baldwin, T. T. (2004). Setting the stage for effective leadership: Antecedents of transformational leadership behavior. Leadership Quarterly, 15, 195-210.

10. Bono, J. E., \& Judge, T. A. (2004). Personality and transformational and trasactional leadership: A meta-analysis. Journal of Applied Psychology, 89(5), 901-910

11. Brandt, T. \& Laiho, M. (2013) Gender and personality in transformational leadership context. An examination of leader and subordinate perspective. Leadership \& Organization Development Journal, Vol. 34, Nr. 1, pp. 44-66.

12. Brown, F. W., \& Reilly, M. D. (2009). The Myers-Briggs type indicator and transformational leadership. Journal of Management Development, 28(10), 916-932.

13. Burke, J.M. \& Attridge, M. (2011). Pathways to career and leadership success: Part 1 - A psychosocial profile of \$100k professionals. Journal Of Workplace Behavioral Health, 26(3), 175-206

14. Burns, J. M.G., 1978. Leadership. New York: Harper \& Row, Publishers, Inc.

132 Review of International Comparative Management Volume 19, Issue 1, May 2018 
15. Chan, K. Y., \& Drasgow, F. (2001), Toward a theory of individual differences and leadership: Understanding the motivation to lead. Journal of Applied Psychology, 86: 481-498

16. Conger, J. A., \& Kanungo, R. N. (1987). Toward a behavioral theory of charismatic leadership in organizational settings. Academy of Management Review, 12, 637-647

17. El Toufaili, B. (2017). The Effects of Transformational Leadership On Organizational Performance-A Theoretical Approach. In Proceedings of the International Management Conference (Vol. 11, No. 1, pp. 153-163). Faculty of Management, Academy of Economic Studies, Bucharest, Romania.

18. Gardner, J. W. (1990). On leadership. New York, NY: The Free Press.

19. Gardner, W. L., \& Avolio, B. J. (1998). The charismatic relationship: A dramaturgical perspective. Academy of Management Review, 23, 32-58

20. Garofoli G. (2002), Local Development in Europe: Theoretical Models and International Comparisons, European Urban and Regional Studies, vol. 9, n. 3, pp. $225-239$

21. Gîrneață, A., \& Potcovaru, M. (2015). The Influence of Organizational Culture in Increasing the Performance of Textile and Clothing Companies. In The 4th Multidisciplinary Academic Conference in Prague, Czech Republic," Proceedings of The 4th MAC.

22. Gladwell, Malcolm (2005). Blink: The power of thinking without thinking. New York: Little, Brown and Company.

23. Goleman, D. (1998). Working with emotional intelligence. New York: Bantam Books

24. Greenleaf, R. (1998). The power of servant leadership. San Francisco, CA: BerrettKoehler Publishers, Inc.

25. House, R. J., \& Howell, J. M. (1992). Personality and charismatic leadership. Leadership Quarterly, 3, 81-108.

26. Jackson, C. K. (2013). Non-cognitive ability, test scores, and teacher quality: Evidence from 9th grade teachers in North Carolina. Working Paper 18624, NBER

27. Judge, T. A., \& Bono, J. E. (2000). Five-factor model of personality and transformational leadership. Journal of Applied Psychology, 85, 751-765

28. Judge, T. \& Piccolo, R. (2004).Transformational and Transactional Leadership: A Meta-Analytic Test of Their Relative Validity, Journal of Applied Psychology, 5, 755-768.

29. Kaufman, J., Synnot, A., Ryan, R., Hill, S., Horey, D., Willis, N., Robinson, P. (2013). Face to face interventions for informing or educating parents about early childhood vaccination. Cochrane Database of Systematic Reviews, Issue $5,1-89$

30. Kirkpatrick, S. A. and Locke, E. A. (1991) 'Leadership: Do Traits Matter?, Academy of Management Executive 5(2): 48-60 
31. Lee, E. (2012) Big Five Personality Traits and Equity Sensitivity and Transformational Leadership. International Journal of Social Science and Humanity, Vol. 2, Nr. 2, pp. 164- 167

32. Marzano, R., \& Waters, T. (2009). District leadership that works: Striking the right balance. Bloomington, IN: Solution Tree Press

33. McCrae RR, John OP (1992). An introduction to the five-factor model and its applications. J. Pers., 60: 175-215.

34. McCrae, R. R., \& Costa, P. T. Jr. (1997). Conceptions and correlates of openness to experience. In R. Hogan, J. A. Johnson, \& S. R. Briggs (Eds.), Handbook of personality psychology (pp. 825-847). San Diego, CA: Academic Press

35. Muchiri, M.K., Cooksey, R.W. şi Walumbwa, F.O. (2012) Transformational and social processes of leadership as predictors of organisational outcomes. Leadership \& Organization Development Journal, Vol. 33, Nr. 7, pp. 662-683

36. Năstase, M., Crăciun, L, Tănase; Vizitiu, C., (2015), Leadership in Romanian Small to Medium Enterprises, Sustainability 7, no. 4: 4183-4198

37. Perkins-Gough, D. (2013). The significant of grit: A conversation with Angela Lee Duckworth. Educational Leadership, 71(1), 14-20

38. Potcovaru, A. M., \& Girneata, A. (2015). The role of the human resources in improving the organizational performance in healthcare sector. In The 4th Multidisciplinary Academic Conference in Prague (pp. 1-9).

39. Robbins, S.P. \& Judge, T.A. (2011). Organizational Behavior. (Fourteenth ed.). England: Pearson.

40. Rubin, R. S., Munz, D. C., \& Bommer, W. H. (2005). Leading from within: The effects of emotion recognition and personality on transformational leadership behavior. Academy of Management Journal, 48, 845-858.

41. Schneider, B., Paul, M. C., White, S. S., \& Holcombe, K. M. (1999). Understanding high school student leaders, I: Predicting teacher ratings of leader behavior. The Leadership Quarterly, 10(4), 609-636

42. Shamir, B., Arthur, M. B., \& House, R. J. (1994). The rhetoric of charismatic leadership: A theoretical extension, a case study, and implications for research. Leadership Quarterly, 5, 25-42

43. Shivers-Blackwell, S. (2006) The influence of perceptions of organizational structure and culture on leadership role requirements: the moderating impact of locus of control and self-monitoring. Journal of Leadership \& Organizational Studies, Vol. 12, Nr. 4, pp. 27-49.

44. Stackman, R.W. \& Devine, K. (2011). Leadership and "emotional-rational" coherence: A start? The Academy of Management Perspectives, 25(1), $42-44$

45. Stogdill, R.M. (1974). Handbook of leadership: A survey of the literature, New York: Free Press

46. Voelker, D. K., Gould, D., \& Crawford, M. J. (2011). Understanding the experience of high school sport captains. The Sport Psychologist, 25, 47-66

47. Waldman DA, Balthazard PA, Peterson SJ (2011), Leadership and neuroscience: Can we revolutionize the way that inspirational leaders are 
identified and developed? Academy of Management Perspective 25(1): 60-74

48. Watson, D., \& Clark, L. A. (1997). Extraversion and its positive emotional core. In R. Hogan, J. Johnson, \& S. Briggs (Eds.), Handbook of personality psychology (p. 767-793). San Diego, CA: Academic Press

49. Wiggins, J. S., \& Trapnell, P. D. (1996). A dyadic-interactional perspective on the five-factor model. In J. S. Wiggins (Ed.), The five-factor model of personality: Theoretical Perspectives (pp. 88-162). New York, NY: Guilford

50. Yukl, G.A. (1998) An evaluation of conceptual weaknesses in transformational and charismatic leadership theories. Leadership Quarterly, Vol. 10, Nr. 4, pp. 285-305

51. Zaccaro, S. J., Kemp, C., \& Bader, P. (2004). Leader traits and attributes. In J. Antonakis, A. T. Cianciolo, and R. J. Sternberg (Eds.), The nature of leadership (pp. 101-124). Thousand Oaks, CA: Sage 